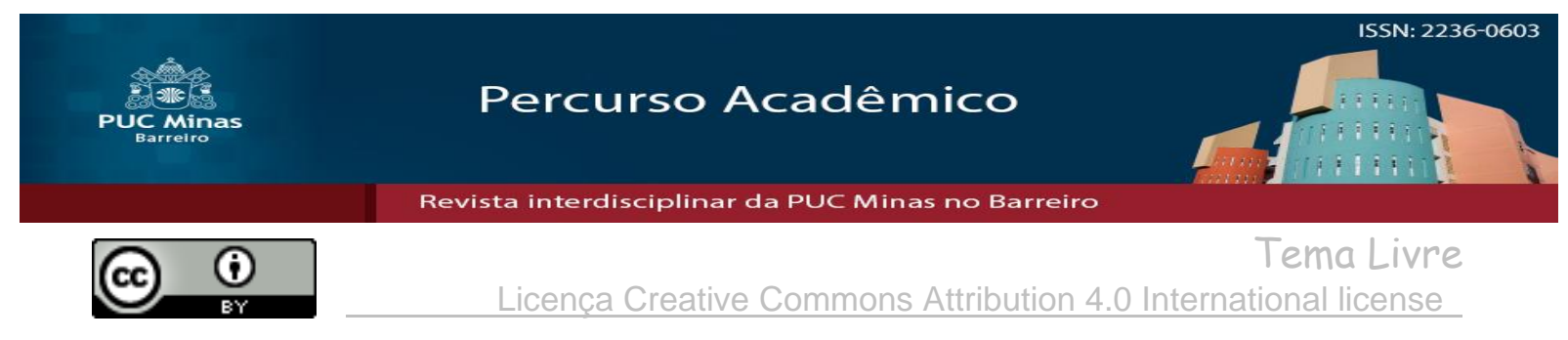

\title{
Análise da gestão de remuneração nas melhores empresas para trabalhar em 2019, no Brasil
}

Analysis of compensation management in the best companies to work in 2019 in Brazil

\author{
Roseli Chaves ${ }^{1}$ \\ Luiz Claudio de Lima ${ }^{2}$
}

\begin{abstract}
RESUMO
As políticas da gestão de remuneração são de inteira responsabilidade das organizações e os empregados esperam transparência nos processos de movimentações horizontais (progressões salariais) e verticais (promoções), além de uma remuneração que seja justa e equitativa internamente e competitiva em relação ao mercado de trabalho. Esses são elementos fundamentais para que o empregado se sinta reconhecido, valorizado e com oportunidade de crescimento pessoal e profissional. O objetivo deste artigo é analisar as políticas e práticas de gestão de remuneração nas melhores empresas para se trabalhar eleitas pela Revista Você S.A., em 2019. Foi realizada uma pesquisa descritiva, com dados secundários que constam na referida publicação. Para tanto, foi utilizada a análise de conteúdo para averiguar as informações das 50 empresas melhor avaliadas em gestão de remuneração. Conclui-se que, dentre as subcategorias mais comentadas pelas empresas e seus empregados, salários, bônus, prêmios, PLR, vantagens e benefícios são os mais citados. Isso indica que tais formas de recompensar os empregados fazem parte das estratégias de remuneração das empresas melhor avaliadas pela revista, demonstrando uma utilização mais ampla de formas indiretas de remuneração, que reduzem os encargos e os custos das empresas. Observa-se também que existe espaço para que as empresas ampliem o alinhamento entre suas necessidades e as expectativas dos empregados em relação à remuneração, gerando, assim, melhores resultados e maior satisfação para os empregados.
\end{abstract}

Palavras-chave: Gestão de Pessoas. Gestão de Remuneração. Melhores Empresas para Trabalhar.

\begin{abstract}
Compensation management policies are entirely responsibility of organizations and employees expect transparency in the processes of horizontal movements (wage progressions) and vertical movements (promotions), in addition to a remuneration that is fair and equitable internally and competitive in relation to the job market. These are fundamental elements for the employee to feel recognized, valued and with an opportunity for personal and professional growth. The purpose of this article is to analyze the remuneration management policies and practices in the best companies to work for elected by Você S/A magazine in 2019. Descriptive research was carried out with secondary data contained in that publication. For this, content analysis was used to ascertain the information of the 50 best rated companies in Remuneration
\end{abstract}

\footnotetext{
${ }^{1}$ Mestra em Administração pela Fundação Mineira de Educação e Cultura (FUMEC), Especialização em Gestão Estratégica de Pessoas pela Universidade Federal de Minas Gerais (UFMG) e Graduação em Ciências Contábeis Pontifícia Universidade Católica de Minas Gerais (PUC MG), Brasil. E-mail: chavesrosinha@hotmail.com

${ }^{2} \mathrm{PhD}$ em Administração pela Universidade FUMEC, Mestre em Engenharia da Produção pela Universidade Federal de Santa Catarina, Graduado em Administração pela Universidade FUMEC, Especialista em Gestão de Recursos Humanos e Consultoria Organizacional pela Faculdade de Ciências Gerenciais da Una. Atualmente é Consultor Organizacional e Professor Titular da Universidade FUMEC. Brasil.E-mail:1cl@fumec.br
} 
Management. It is concluded that, among the subcategories most commented on by companies and their employees: salaries, bonuses, prizes, PLR (Profit Sharing Program), advantages and benefits, are the most cited. This indicates that these forms of rewarding employees are part of the remuneration strategies of the companies best evaluated by the magazine, indicating a wider use of indirect forms of remuneration, which reduce the burden and costs of the companies. It's also possible to notice that there is space for companies to amplify the alignment between their necessities and the expectations about the remuneration, causing best results and more satisfaction on the employees.

Keywords: People management. Remuneration Management. Best Companies to Work For.

\section{INTRODUÇÃO}

As mudanças no mundo do trabalho advindas da tecnologia e da reforma trabalhista trazem novas possibilidades, demandando uma estrutura de cargos mais flexível e mais enxuta, com novos modelos de remuneração, para que os funcionários sejam recompensados conforme sua contribuição, de acordo com as metas estipuladas pela empresa e não pelo cargo, o que não mais atende às situações existentes no ambiente de trabalho. (ORSI, 2017).

A política de remuneração traz o modelo de remuneração adotado pelas empresas, tradicional ou estratégico, ou seja, a remuneração é baseada nos cargos, no modelo tradicional ou estratégico, por meio das metas e resultados alcançados pelos empregados alinhados à estratégia organizacional. O modelo tradicional não atende todas as situações do ambiente organizacional, por isso, devem ser avaliados os grupos ocupacionais e o contexto para definir o melhor modelo de remuneração por área ou empresa. (ORSI, 2017).

A política de remuneração pode ser avaliada em relação aos desvios dos valores praticados pelo mercado de trabalho. A mediana separa a metade dos salários maiores da outra metade dos salários menores. Se os salários estão na mediana, estão ajustados; se o salário está abaixo de 30\% em relação à mediana, é considerada uma situação crítica e, em $15 \%$, defasada. Já $15 \%$ acima da mediana são competitivos e 30\% acima, agressivos. (ORSI, 2017). Entende-se que, para ser uma boa empresa para se trabalhar, as pessoas precisam ter a percepção de justiça em toda a hierarquia, em relação à remuneração, às avaliações e aos reajustes acima da inflação. (ARAÚJO; GARCIA, 2010).

A pesquisa Flight risk in M\&A: the art and science of retaining talent (Risco de Perda em Fusão e Aquisição: a arte e a ciência de reter talentos), realizada pela empresa Mercer, que é líder global em serviços de consultoria nas áreas de capital humano, benefícios, pensões e investimentos, mostrou que a retenção de empregados é a principal preocupação como risco percebido. Mais de 7 em 10 empresas (71\%), em todo o mundo, 
dizem utilizar incentivos financeiros para retenção de talentos, como parte de sua estratégia. (MERCER, 2017). A equidade dos salários e a transparência nos pagamentos evitam a injustiça, promovem a autonomia e aumentam a eficácia. (MORIATY, 2018).

O rigor da análise faz com que a pesquisa "Melhores empresas para trabalhar", realizada pelo Progep - FIA, publicada pela Editora Abril e divulgada na Revista Você S/A, sirva de benchmarking em todo o país. Deve-se isso ao fato de esse guia, ou seja, documento com o resultado da pesquisa, ser a única pesquisa de clima organizacional no Brasil, em que repórteres especializados vão até as empresas pré-classificadas, para conversarem em particular, com os funcionários e entenderem como eles se sentem no ambiente de trabalho, em relação às políticas e práticas de remuneração.

Dessa forma, este estudo busca responder a seguinte questão: quais as estratégias de remuneração mais utilizadas nas Melhores Empresas para se Trabalhar, eleitas pela Revista Você S.A., em 2019?

\section{REFERENCIAL TEÓRICO}

\subsection{Gestão de Pessoas}

A área de Recursos Humanos possui múltiplos papéis, com foco principalmente em resultados. Dentre suas atividades, está a gestão de remuneração, pois, se ela estiver alinhada com a estratégia, os empregados poderão ser recompensados conforme suas entregas. (ULRICH, 2000).

O Quadro 1 apresenta, na visão de Pereira (2014), a perspectiva de atuação do RH tradicionalmente e, por outro lado, o Recursos Humanos de forma estratégica.

Quadro 1 - Comparativo entre o RH tradicional e o RH estratégico 


\begin{tabular}{|l|l|}
\hline RH TRADICIONAL & RH ESTRATÉGICO \\
\hline Foco em processos e tarefas: & Foco em resultados estratégias: \\
\hline $\begin{array}{l}\text { Recrutamento e seleção voltados } \\
\text { para o cargo. }\end{array}$ & $\begin{array}{l}\text { Captação de capital intelectual no mercado, para } \\
\text { dinamização do negócio. }\end{array}$ \\
\hline Treinamento na função. & Aprendizado e educação continuados. \\
\hline $\begin{array}{l}\text { Gestão de cargos / Salário. } \\
\text { Relações trabalhistas } \\
\text { estagnadas. }\end{array}$ & Gestão de competências. \\
\hline $\begin{array}{l}\text { Manutenção de processos e } \\
\text { tarefas. }\end{array}$ & $\begin{array}{l}\text { Parcerias e negociações / Cultura de mudança e } \\
\text { inovação. }\end{array}$ \\
\hline
\end{tabular}

Fonte: PEREIRA, 2014, p. 23.

$\mathrm{O}$ antigo papel do RH era voltado para a burocracia e a centralização das atividades da área e não se comunicava com as outras áreas. Já o novo RH requer novos papéis, como definir normas alinhadas à legislação vigente; ser um facilitador de RH para todas as unidades; apoiar o recrutamento e a seleção das unidades e os funcionários nos processos de mudança, abraçando a inovação, aprendendo novos sistemas e sendo premiados conforme o desempenho individual. (RIBEIRO, 2019).

\subsection{Gestão de Remuneração}

O salário é o principal item do rol de recompensas oferecido pelas organizações. Os funcionários recebem de acordo com o cargo, dentro do limite mínimo e máximo da faixa salarial. Nesse caso, para a realização do pagamento, observa-se o cargo ocupado e sua hierarquia. (HIPÓLITO, 2002).

O salário fixo, direto ou base é o mínimo que o funcionário pode receber, e é independente do desempenho. Já a remuneração pode ser indireta, com benefícios fixos ou flexíveis, e a variável que depende do desempenho dos funcionários. (PEREIRA, 2014).

O Quadro 2 apresenta os diversos tipos de salários e suas definições na concepção de Marras.

Quadro 2 - Definições de salário 


\begin{tabular}{|c|l|}
\hline Tipo de Salário & Definição \\
\hline 1. Salário nominal & $\begin{array}{l}\text { É aquele que consta na ficha de registro, na carteira profissional } \\
\text { e em todos os documentos legais. Pode ser expresso em hora, } \\
\text { dia, semana, mês etc. }\end{array}$ \\
\hline 2. Salário efetivo & $\begin{array}{l}\text { É o valor efetivamente recebido pelo empregado, já } \\
\text { descontadas as obrigações legais (INSS, IR etc.). }\end{array}$ \\
\hline 3. Salário complessivo & $\begin{array}{l}\text { É o que tem inserido no seu bojo toda e qualquer parcela } \\
\text { adicional (hora extra etc.). }\end{array}$ \\
\hline 4. Salário profissional & $\begin{array}{l}\text { É aquele cujo valor está expresso na lei e se destina } \\
\text { especificamente a algumas profissões (por exemplo, médicos, } \\
\text { engenheiros). }\end{array}$ \\
\hline 5. Salário relativo & $\begin{array}{l}\text { É a figura de comparação entre um salário e outro na mesma } \\
\text { empresa. }\end{array}$ \\
\hline 6. Salário absoluto & $\begin{array}{l}\text { É o montante que o empregado recebe, líquido de todos os } \\
\text { descontos, e que determina seu orçamento. }\end{array}$ \\
\hline
\end{tabular}

Fonte: MARRAS, 2016, p. 78.

Com o desenvolvimento das empresas, novas tecnologias e suas complexidades e as limitações no sistema de recompensa por cargo, surgiram outros modelos para atenderem às necessidades das organizações. No modelo de cargos, podem ser utilizadas definições de cargos mais abrangentes e genéricas e faixas mais largas para atenderem ao processo de mudança. (HIPÓLITO, 2002).

Faz-se necessário que a organização adote práticas que atraiam profissionais com habilidades, conhecimentos e atitudes adequados às suas necessidades. O salário e os benefícios podem ser fatores decisivos na atração de pessoas. Depois dessa atração, as empresas precisarão de práticas que as diferenciem do mercado e fidelizem os funcionários. Segundo Wood Júnior e Picarelli (2004), algumas empresas oferecem pacotes de benefícios como vantagem competitiva para a atração e retenção das pessoas, principalmente em funções de alto nível de responsabilidade e de capacitação profissional.

A maioria dos benefícios não é estabelecida pela CLT, são concedidos pelas empresas como fruto das negociações realizadas pelos sindicatos das categorias. Os benefícios fazem parte da remuneração indireta paga aos empregados e os mais utilizados no mercado são: seguro de vida, restaurante, transportes, festas, cesta básica, assistência médica, veículo designado, seguro de acidentes pessoais, clube, assistência odontológica e pagamento de quilometragem. (THEOTÔNIO; REIS NETO; LOPES, 2013).

Os planos tradicionais não levam em consideração a diversidade das necessidades dos empregados ao disponibilizarem os benefícios e promovem a padronização, que, 
muitas vezes, pode não agradar ou ser desperdiçada pelos empregados. Os novos modelos de benefícios são os pacotes de benefícios, que os empregados recebem como um cardápio, para escolherem segundo suas necessidades, observando o limite disponibilizado, sendo que a empresa pode manter alguns benefícios como obrigatórios. (ARELLANO; CESAR, 2017).

No Quadro 3, são apresentados os tipos de benefícios oferecidos pelas empresas, que proporcionam apoio às necessidades dos funcionários e seus familiares.

Quadro 3 - Tipos de benefícios

\begin{tabular}{|l|l|}
\hline $\begin{array}{l}\text { Tipos } \\
\text { benefícios }\end{array}$ & Exemplos de benefícios \\
\hline Financeiros & $\begin{array}{l}\text { Adiantamento quinzenal salarial, adiantamento de 13 para } \\
\text { todos, empréstimos de emergência, posto bancário na empresa, } \\
\text { pagar diretamente na empresa certos benefícios sociais, plano } \\
\text { de complemento de aposentadoria, complementar o auxílio } \\
\text { doença. }\end{array}$ \\
\hline De saúde & $\begin{array}{l}\text { Plano médico e odontológico, convênio com óticas, convênio } \\
\text { com farmácias, exames médicos periódicos, médico no local de } \\
\text { trabalho, programas preventivos, cursos voltados para o } \\
\text { funcionário e a família. }\end{array}$ \\
\hline Alimentares & $\begin{array}{l}\text { Oferecer refeitório, restaurante na empresa, serviço de café e } \\
\text { lanches, vale refeição e cesta básica. }\end{array}$ \\
\hline Educacionais & $\begin{array}{l}\text { Oferta de cursos, bolsa de estudos, indicação para cursos } \\
\text { profissionalizantes e oferta de estágios para filhos de } \\
\text { empregados. }\end{array}$ \\
\hline Familiares & $\begin{array}{l}\text { Pontes e folgas em feriados, horário flexível, creche no local de } \\
\text { trabalho, auxílio creche, programas de vacinação infantil, kit de } \\
\text { nascimento de filho, cesta básica. }\end{array}$ \\
\hline
\end{tabular}

Fonte: RIBEIRO, 2019, p. 102.

A gestão de remuneração se traduz por meio das normas e diretrizes que devem ser seguidas em toda a estrutura organizacional. Essa política deve estar alinhada com a diretoria, para que possa atender à sua missão e aos seus objetivos. Nela devem constar cargos, fatores de avaliação de cargos, classificação e faixa de cargos, faixas salariais, critérios para aumento por mérito, promoções, manutenção das estruturas, pesquisas salariais, reajustes gerais, controles, revisão de descrições, revisão das avaliações de cargos e dos novos. (MARRAS, 2016).

O salário admissão é destacado em algumas convenções coletivas, com a garantia aos empregados admitidos para a mesma função, sem considerar vantagens pessoais. Em outras, o salário é alterado ao se completarem 90 dias (contrato de experiência) e menciona alguns pisos salariais. (MARRAS, 2016). 
Na Consolidação das Leis Trabalhistas - CLT, remuneração é o conjunto de prestações recebidas habitualmente pelo empregado, pela prestação de serviços, seja em dinheiro ou em utilidades, provenientes do empregador ou de terceiros, mas decorrentes do contrato de trabalho, de modo a satisfazer suas necessidades básicas e de sua família. A remuneração é composta de: horas extras, adicional noturno, adicional de periculosidade, adicional de insalubridade, descanso semanal remunerado, comissões, prêmios habituais, gratificações, gorjetas, ajuda de custo habitual. O salário in natura é o fornecimento habitual de qualquer vantagem concedida ao empregado, tais como, aluguel de casa, veículo, escola para os filhos etc. A remuneração inclui o salário fixo e outras importâncias recebidas. (BRASIL, 2017).

A gestão de remuneração é um importante processo da área de Gestão de Pessoas nas organizações, segundo Araújo e Garcia (2010), Nawaz e Pangil (2016), Grubb (2018) e Ribeiro (2019).

Na opinião de Basile (2018), o piso salarial ou salário normativo é o menor valor que os trabalhadores podem receber segundo a categoria profissional. Geralmente, é negociado em convenção coletiva, mas também pode ter previsão legal.

A política salarial descreve as normas e os elementos da estrutura salarial: o piso mínimo e máximo de cada cargo, o salário admissão adotado pela categoria e pela empresa, as promoções horizontais e verticais e as reclassificações dos cargos frente às mudanças internas e externas. As empresas que possuem funcionários com salários abaixo do piso, ajustados ao se completar o contrato de experiência, ou que admitem com salário acima do piso devem incluir os critérios na política salarial. Na promoção horizontal, os funcionários recebem aumento salarial por mérito, sem alteração da função, e, em geral, observam o prazo de um ano na função. Já na promoção vertical, ocorre mudança do nome da função e do salário e, em geral, observam o prazo de seis meses ou outro prazo estipulado pela empresa. Essas alterações ocorrem porque os funcionários alcançam desempenho superior nas suas atividades e aumento da experiência. (PONTES, 2019).

A reclassificação da função ocorre quando o funcionário desenvolve atividade mais complexa que o cargo atual. Já as promoções por antiguidade, utilizadas no serviço público, observam o prazo de dois anos na função para nova movimentação. (PONTES, 2019). 


\subsection{Remuneração tradicional e remuneração estratégica}

O modelo tradicional é centrado no cargo, como um conjunto de funções com uma posição definida na estrutura organizacional. Os salários e benefícios são determinados a partir da segmentação e definição das funções do empregado. As premissas desse sistema são a classificação, que é desenvolvida a partir da dimensão das tarefas típicas de determinado cargo, que são consideradas fatores estáticos de diferenciação das pessoas, não necessariamente vinculadas à sua capacidade e ao seu potencial, muito menos ainda à sua contribuição para os resultados. Esse enfoque prevê a equidade salarial externa (salários da organização alinhados ao mercado). (DUTRA, 2019).

A maioria das empresas utiliza o modelo tradicional de remuneração, que acompanha o cargo e sua posição na hierarquia, com burocracias rígidas, inflexíveis e conservadoras. Mas as relações de trabalho mudaram e não faz mais sentido remunerar baseado em responsabilidade e descrição de atividades. A remuneração estratégica pode ser paga de várias formas aos seus funcionários, de acordo com a sua contribuição para a estratégia, que também leva em consideração as suas competências. (WOOD JÚNIOR, 2009).

A remuneração estratégica complementa a remuneração tradicional, sendo que a tradicional paga o salário fixo de acordo com as responsabilidades e os limites do cargo. $\mathrm{Na}$ remuneração estratégica, os empregados têm possibilidade de ganhar melhor de acordo com sua contribuição para os resultados da empresa. Existem vários modelos de remuneração estratégica. No modelo de remuneração por habilidade, a remuneração é direcionada aos cargos operacionais, os empregados desenvolvem o seu nível de habilidade e avançam nos níveis salariais. Esse modelo é pouco praticado pela sua similaridade com o processo de treinamento e desenvolvimento e não como sistema de remuneração. Isso porque pressupõe que todo empregado que queira avançar financeiramente busque desenvolver novas habilidades de acordo com as metas e os conhecimentos necessários ao seu desenvolvimento. (MARRAS, 2016).

O modelo de remuneração por competência é direcionado aos cargos de liderança. A competência não está ligada a características pessoais, e sim, ao conhecimento, o que a pessoa domina. A remuneração estratratégica é aquela que permite premiar o funcionário que se destaca perante os outros, considerando-se os fatores que impactam nos resultados da organização. Seus pilares são: conhecimentos, habilidades e atitudes, por meio dos quais a empresa recompensa. Segundo o referido autor, são poucas as 
empresas que empregam sistemas remuneratórios estratégicos, pois a maioria está em processo embrionário. (MARRAS, 2016).

O sistema de remuneração tradicional é o mais utilizado no Brasil, quando comparado com os modelos anteriores. Algumas organizações fazem benchmarking de práticas no exterior, e precisam adaptar à realidade nacional, como cultura e legislação trabalhista.

Já a remuneração estratégica como remuneração variável é mais utilizada. Para Huczok e Leme (2014), a gestão por competência serve para o desenvolvimento dos colaboradores e não como sistema de remuneração, pois não pode depender de mapeamento das competências, com pouca subjetividade, falta de vínculo com resultados e que dependam de opiniões de pessoas para remunerar os empregados. Empresas que pagam apenas por competência podem incorrer em várias situações, como inchaço da folha de pagamento, com critérios subjetivos de avaliação e os mesmos resultados, funcionários no topo das competências e outros insatisfeitos por falta de verba. E sugere que as empresas tenham sistemas integrados, plano de cargos e salários, sistema de gestão de competência e avaliação de desempenho, com algum indicador, como coeficiente de desempenho do colaborador, que unifique esses sistemas com critérios e políticas para movimentação de salário. (HUCZOK; LEME, 2014).

Esses autores convergem com Dutra (2019), que fala sobre a dificuldade em mensurar a contribuição dos empregados e possibilitar a ascensão pelo conceito do CHA - Conhecimento, Habilidade e Atitude, por serem fatores intangíveis, e propõe o conceito de complexidade, com fatores tangíveis, ou seja, ligados a atribuições e responsabilidades dos empregados e seu nível de contribuição. O conceito de complexidade pode integrar remuneração, carreira e desenvolvimento. Nesse sentido, podemos entender que a pessoa terá aumento salarial ou promoção quando ela incorporar novas atribuições e responsabilidades de outro nível de complexidade.

O modelo de remuneração acionária é aplicado aos níveis estratégicos. Os gestores passam a ser acionistas da organização e mais comprometidos, pois têm retorno com a valorização das ações, sendo uma das formas de premiar os empregados mediante seus resultados.

Já o modelo de distribuição de ganhos é utilizado nas esferas operacionais, intermediárias da hierarquia organizacional, em programas de ideias e melhorias de processos. $\mathrm{O}$ valor economizado é revertido aos empregados. 
No modelo com participação nos lucros, as empresas que obtiverem lucro em certo período são obrigadas a repassar um percentual aos seus empregados, de acordo com as normas estabelecidas em acordos e convenções coletivas.

Finalizamos com o modelo de remuneração por resultados, que é um dos modelos mais utilizados, pois foca seu recebimento no atingimento das metas. Dentre esses modelos, apenas a participação nos lucros tem respaldo legal. Os demais precisam ser avaliados e estruturados para evitar problemas futuros. (MARRAS, 2016).

Verifica-se que a estratégia de recompensa e o sistema de recompensa implementado têm impacto positivo para o desempenho organizacional. Em relação ao desempenho financeiro, aumentam as vendas e geram maior receita para a organização. Não financeiramente, ajudam a cumprir os objetivos estratégicos da organização, especialmente na perspectiva de recrutamento e crescimento organizacional. (SAN; THEEN; HENG, 2012).

Conforme o Art. $3^{\circ}, \S 1^{\circ}$ da Lei 10.101, as parcelas da participação nos lucros e resultados pagos aos empregados podem ser deduzidas como despesas operacionais, dentro do exercício legal, pelas empresas tributadas pelo lucro real. A lei determina que o pagamento da PLR seja semestral ou anual, sendo que pagamentos em outros períodos são descaracterizados. Em algumas convenções coletivas, já existem a obrigatoriedade e as regras do pagamento da PLR, mas muitas empresas fazem um acordo com os empregados e sindicatos para pagamento da PLR ou do plano complementar da PLR. Uma parcela do lucro é repassada aos funcionários, em certo período do ano. (BRASIL, 2000).

Os objetivos desse repasse são reforçar o atendimento aos objetivos organizacionais, reter e manter profissionais qualificados, aumentar a remuneração, diminuir o turnover e permitir ao empregado usufruir da riqueza da organização. $\mathrm{O}$ programa da PLR deve ser ajustado entre empregadores e empregados e mediado pelos sindicatos da categoria. Deve ser definida uma comissão mista, indicada pelas partes, para realizarem tal tarefa, por acordo ou convenção coletiva. O programa precisa ter normas claras e objetivas e as metas e indicadores bem definidos, com períodos e prazos para apuração e pagamento e revisão do contrato. (THEOTÔNIO; REIS NETO; LOPES, 2013).

Os componentes do sistema de remuneração estratégico incluem parte fixa, funcional e competências, conforme o Quadro 4. O salário funcional é inerente ao cargo ocupado e nas empresas que utilizam esse sistema, os funcionários são remunerados pela 
sua função e isso ocorre predominantemente em empresas hierárquicas. Já a remuneração por competência busca o desenvolvimento contínuo dos funcionários e é submetida a empresas que precisam de funcionários constantemente atualizados; e vincula esse progresso ao aumento salarial e ao desempenho dos funcionários. A remuneração variável é ligada ao desempenho dos funcionários, à área, à empresa, além de incluir sugestões premiadas, participação acionária, participação nos lucros ou resultados, bônus, comissão, prêmios. Na remuneração indireta, benefícios fixos e flexíveis. O pagamento é feito por meio de comissão e bônus para o pessoal de vendas; para os executivos, pagamento de bônus; e, para os operacionais, os prêmios. Mas, por meio da participação nos lucros ou resultados, após a aprovação da Lei 10.101 , no Art. $3^{\circ}, \S 1^{\circ}$, e com respaldo jurídico, passa ser para todos, sendo descrita em muitos acordos coletivos de trabalho. A remuneração variável ligada aos objetivos da organização é a principal modalidade de remuneração estratégica, porque todos ganham. (PONTES, 2019).

Quadro 4 - Sistema estratégico

\begin{tabular}{|l|c|c|c|}
\hline $\begin{array}{l}\text { Componentes da } \\
\text { Remuneração } \\
\text { estratégica }\end{array}$ & \multicolumn{3}{|c|}{ Tipos } \\
\hline Parte fixa (salário) & Funcional & Competências & \\
\hline $\begin{array}{l}\text { Parte móvel } \\
\text { (Remuneração } \\
\text { variável) }\end{array}$ & $\begin{array}{l}\text { Sugestões } \\
\text { premiadas }\end{array}$ & $\begin{array}{c}\text { Participação } \\
\text { Acionária }\end{array}$ & $\begin{array}{c}\text { Participação nos } \\
\text { Lucros ou } \\
\text { Resultados }\end{array}$ \\
\cline { 2 - 4 } & Bônus & Comissão & Prêmios \\
\hline Salário Indireto & Benefícios Fixos & Benefícios Flexíveis & \\
\hline
\end{tabular}

Fonte: PONTES, 2019.

Conforme alteração da legislação trabalhista, Lei 13.467/2017, prêmios não integram mais a base de cálculo para previdência. (BRASIL, 2017).

Se as organizações desejam incluir recompensas totais como parte de suas estratégias de engajamento, é imperativo que elas entendam a natureza complexa na relação recompensa-engajamento e qual a melhor maneira de usar sistemas de recompensa para atender às necessidades e aos objetivos da organização e dos funcionários. Certas recompensas são melhores preditoras de envolvimento no trabalho do que outras, o que implica que as empresas devem se afastar do modelo único de estratégias de recompensa. (HOOLE; HOTZ, 2016).

Em empresas mais hierarquizadas, é mais utilizado o salário fixo, pois impera a formalidade e a importãncia das funções, a autoridade e seus limites. Nas empresa onde 
imperam inovação, flexibilidade, empreendedorismo, criatividade, o salário por competência deve ser estimulado. Em empresas movidas por projetos, a remuneração móvel é baseada em indicadores de desempenho. A política de remuneração está ligada ao tipo de organização, sua cultura, tipo de negócio e estratégias. (PONTES, 2019).

A existência do comitê de remuneração apoia nas decisões, nos debates e nas divulgações de remuneração. Ou seja, a extensão da divulgação e a tendência a fornecer atribuições internas aumentam com a qualidade do comitê de remuneração. No geral, esses resultados sugerem que a presença e a qualidade dos comitês de remuneração aprimoram a prestação de contas corporativa, aperfeiçoando as divulgações sobre as decisões de remuneração de executivos e a tendência do conselho de assumir responsabilidade pelas decisões de remuneração. (KANAPATHIPPILLAI; MIHRET; JOHL, 2019).

\section{METODOLOGIA}

Segundo Gil (2007), método científico é um conjunto de procedimentos formais e sistemáticos, escolhidos pelo pesquisador, para alcançar o objetivo proposto e, para alcançar esse objetivo, é preciso escolher as ferramentas adequadas.

Neste estudo, optou-se pela técnica de Análise de Conteúdo, para tratar as práticas de gestão de remuneração, que é o objeto de estudo, pois, segundo Bardin (2016), são técnicas que têm objetivo de avaliar a descrição das mensagens, entrevistas e entender o conteúdo dessas fontes.

Quanto aos fins, neste trabalho, optou-se pela realização de uma pesquisa descritiva, com abordagem qualitativa, pois, segundo Vergara (2004) esse tipo de pesquisa é utilizado quando se pretende descrever determinada população ou fenômeno.

Em relação aos meios, optou-se pela pesquisa documental, que utiliza, como base de dados, as informações que estão disponíveis na pesquisa encomendada pela Revista Você S.A., da Editora Abril, realizada pelo Progep - FIA e publicada no Brasil, no ano de 2019, na sua edição especial, intitulada "Melhores Empresas para Trabalhar (MEPT)". Em unidade de observação: Documentos provenientes da pesquisa realizada pelo Progep - FIA e publicada pela Revista Você S.A., da Editora Abril, intitulada "Melhores Empresas para Trabalhar (MEPT)”, em 2019.

Como técnica de coleta de dados, foi realizada uma seleção de dados secundários, relativos às informações sobre práticas de gestão de remuneração, pertinentes às 50 
empresas melhor avaliadas em gestão da remuneração, da publicação de 2019. Entendese que, ao se escolher as 50 empresas melhor avaliadas pelas práticas de gestão da remuneração, tem-se um número significativo de empresas para se estudar.

$\mathrm{Na}$ análise de dados, as informações foram analisadas por meio da técnica de Análise de Conteúdo, que, segundo Bardin (2016), é um conjunto de técnicas de análise de informações por meio da explicitação, sistematização e expressão das mensagens, com o objetivo de deduzir informações lógicas.

Ainda segundo a autora, essa técnica compreende três etapas: pré-análise, exploração do material, tratamento dos resultados - inferência e interpretação.

Na primeira etapa: pré-análise, as informações são organizadas para facilitar a operacionalização, por meio de quatro processos. O primeiro processo é a leitura flutuante (contato, percepção das informações e transcrição). No segundo processo, ocorre a seleção do que será analisado. No terceiro processo, faz-se a formulação dos objetivos (o que o pesquisador propõe verificar). E o último processo é a elaboração dos indexadores (temas que mais se repetem e que podem ser os índices).

Na segunda etapa: Exploração do material, deve ser realizada a codificação do material em unidades de registro (temas, frases, palavras) e unidades de contexto e a definição das categorias de análise (rubricas que agrupam elementos em comum sob o mesmo título). A categorização, segundo Bardin (2016), deve possuir as seguintes regras: a) Exclusão mútua: a informação não ser classificada em mais de uma categoria. b) Exaustividade: os documentos devem atentar para representar a totalidade da comunicação, c) Representatividade: os documentos devem constar no universo pesquisado, d) Homogeneidade: as informações se referem ao tema e, para a pertinência, a observância deve estar alinhada com o material e o tema.

Na terceira etapa: Tratamento dos resultados, faz-se inferência e interpretação. $\mathrm{Na}$ inferência, deverá ser feita uma análise reflexiva e, na interpretação, a intuição, com operações lógicas, embasadas na teoria, em entendimentos de mundo e situações concretas de seus produtores ou receptores.

\section{APRESENTAÇÃO E DISCUSSÃO DOS RESULTADOS}

O presente estudo utilizou os dados do Guia VOCÊ S.A.: "As melhores empresas para se trabalhar de 2019”. A publicação lista as 150 empresas com as melhores 
avaliações em seu ambiente organizacional, com base em dois índices: O Índice de Qualidade do Ambiente de Trabalho (IQAT), no qual funcionários avaliam a companhia, e o Índice de Qualidade de Gestão de Pessoas (IQGP), em que a Fundação Instituto de Administração (FIA) e a Revista VOCÊ S.A. analisam as práticas da empresa. Os dois índices são divididos em 12 categorias de avaliação e são somados IQAT e IQGP, que compõem a nota final da empresa: o Índice de Felicidade no Trabalho (IFT).

Dentre as 150 empresas listadas pela revista, este estudo separou as 50 empresas melhor avaliadas no quesito Gestão da Remuneração.

Na primeira etapa: Pré-análise, as 150 empresas melhor avaliadas em gestão de remuneração foram colocadas em ordem de notas dos índices IQAT. Destas foram selecionadas as $50 \mathrm{com}$ as melhores avaliações em gestão de remuneração. Posteriormente foi realizada uma leitura flutuante sobre as práticas de remuneração e verificou se as informações estavam de acordo com o objetivo e o tema do trabalho aqui apresentado. Foram selecionadas e transcritas todas as informações publicadas pela revista, que estavam relacionadas com o tema remuneração.

Na segunda etapa: Exploração do material, a temática foi incluída no quadro, como unidade de registro. Também foram incluídos os contextos em que a unidade de registro estava inserida, com isso, facilitando a categorização por meio de rubricas, para representarem os grupos que obtiveram maior frequência da palavra Remuneração. As subcategorias encontradas para Remuneração foram: Salário, Bônus, Prêmios, PLR, Benefícios, Vantagens.

Para o entendimento das análises dos dois índices de Qualidade de Gestão de Pessoas e Índice de Qualidade do Ambiente de Trabalho, foram avaliadas as práticas de remuneração e suas respectivas subcategorias.

No Quadro 5 é apresentada a categoria e as subcategorias, bem como os autores que lhes dão sustentação.

Quadro 5 - Categoria e Subcategoria

\begin{tabular}{|l|l|l|}
\hline Categoria & Subcategoria & Autores \\
\hline Remuneração & Salário, Bônus, Prêmios, & (MARRAS, 2016); (HIPÓLITO, \\
& PLR, Vantagens, Benefícios. & 2002); (THEOTÔNIO; REIS NETO; \\
& & $\begin{array}{l}\text { LOPES, 2013); (PONTES, 2019); } \\
\text { (WOOD JR, 2009); (PEREIRA, }\end{array}$ \\
\hline
\end{tabular}




\begin{tabular}{|l|l|}
\hline & 2014); (HOOLE; HOTZ, 2016); \\
& (BRASIL, 2017), (ARELLANO; \\
& CESAR, 2017); (D' SOUZA, 2018); \\
& (BASILE, 2018); (RIBEIRO, 2019); \\
& (ARAUUO; GARCIA, 2010); \\
& (NAWAZ; PANGIL, 2016); \\
(GRUBB, 2018). (DUTRA, 2019); & (MORIATY, 2018); (ORSI, 2017); \\
& (ULRICH, 2000). \\
\hline
\end{tabular}

Fonte: Elaborado pela autora.

Políticas e práticas de gestão da remuneração apresentadas pelas empresas e comentadas pelos empregados como resultado do questionário preenchido por eles.

Na subcategoria Salários, conforme os comentários, as empresas mencionaram sobre suas práticas de salários e relataram que, dependendo do tempo de casa, os funcionários recebem um percentual automático de aumento salarial. Já os funcionários falaram sobre as práticas de salários e reclamaram que a remuneração estava defasada e também desejavam um plano de cargos e salários mais bem definido. Comentaram que existe a equidade salarial entre os gêneros e que os salários poderiam ser mais competitivos. Dentre as reclamações, os funcionários citaram a necessidade de o salário base ser equiparado internamente e externamente; de o novo funcionário não ser admitido para receber mais na mesma função de alguém que já tenha mais tempo na empresa; de adotar o pagamento por meritocracia; que os aumentos sejam com critérios, transparentes; e de não mudarem os critérios de pagamentos sem o consentimento dos funcionários. Tudo isso, traz a sensação de justiça, respeito e imparcialidade. Os benefícios e o Programa de Participação em Resultado (PPR), recebidos como $15^{\circ}$ salário, foram elogiados.

Foram expressos elogios e reclamações, por isso, segundo Kanapathippillai, Milret e Johl (2019), os comitês de cargos e salários apoiam as discussões e soluções dos problemas.

Entende-se, com isso, que salário e políticas salariais não são muito comentados dentro das organizações, pois muitas empresas acreditam que, se divulgarem tais dimensões, podem gerar comparações internas e externas e trazer insatisfações entre os empregados. Diferentemente das empresas públicas, que têm obrigação de divulgar sua estrutura salarial no portal da transparência, as empresas privadas, de acordo com as suas estratégias, podem ou não divulgar suas políticas salariais. 
Na subcategoria Bônus, empresas citaram suas práticas, vinculação do cumprimento de índices de segurança com o recebimento do bônus, com isso, aumentando o comprometimento e engajamento dos funcionários. Na empresa MSD FARMACÊUTICA: “A plataforma Inspire permite a cada funcionário reconhecer e ser reconhecido, a qualquer tempo e o reconhecimento pode ser desde um obrigado até uma aprovação acrescida de valores em dinheiro ou pontos." (VOCÊ S.A, 2019, p. 147). Na empresa GRUPO KYLY: “O Bônus executivo: todos os analistas plenos e os líderes ganham, até dois salários; especialistas e coordenadores, até 4,3 salários; gerentes, até 7,8 salários; e diretores, até 10,5 salários, levando em conta a meta global (80\%) e a individual (20\%).” (VOCÊ S.A, 2019, p.163).

Nas 50 empresas melhor avaliadas que foram pesquisadas, os funcionários não fizeram nenhum comentário referente a bônus, o que leva a entender que essas práticas não são comentadas por eles, porque são poucas empresas que utilizam bônus como parte da sua estratégia de pagamento.

Na subcategoria Prêmios, empresas citaram suas práticas sobre prêmios e procuraram premiar quem se sobressaiu nos times. Como exemplos: quem supera os resultados esperados recebe, das mãos do comitê executivo da empresa, um cartão que vale dinheiro e "os executivos vão até o andar da pessoa para reconhecê-la em público e explicar por que ela mereceu o prêmio", diz Mônica Torquato, gerente de desenvolvimento organizacional da empresa Sodexo. (VOCÊ S.A, 2019, p.163). Na empresa Alelo,

entre 2017 e 2018 a empresa aumentou em $73 \%$ o investimento em programas que distribuem premiações aos funcionários. Entre eles estão o Atitude Alelo e o Mandou Bem, que estimulam os empregados a reconhecer, com dinheiro ou pontos no programa de recompensas Livelo, colegas que se destacaram em alguma atividade. (VOCÊ S.A, 2019, p.163).

Já os funcionários comentaram sobre essas práticas. Elogiaram as recompensas para quem completava períodos significativos atuando na empresa e, dependendo do tempo de casa, recebiam prêmios. Na empresa Águas Guariroba, "a inovação é valorizada e os projetos desenvolvidos pelos trabalhadores podem concorrer a premiações do grupo AEGEA, que vão desde bônus financeiros até viagens e subsídios para cursos”. Ressaltase a importância de reconhecer e premiar os funcionários que se destacam e entregam além das atividades rotineiras.

As empresas apresentaram suas práticas de premiações. Dentre essas práticas, temos: 1) Na empresa Instituto de Pesquisa Eldorado: “Quem é bem avaliada ganha um 
valor extra e quem fica em destaque o ano todo recebe bonificação ou uma viagem como prêmio." (2) Na empresa Renault do Brasil: "Há premiações para as melhores ideias e para os projetos que gerem redução de custos e registros de patentes." (3) Na empresa Grupo KYLY: "Conta com prêmios por produtividade nas unidades de costura." (VOCÊ S.A, 2019, p.163). (4) Na empresa Elanco Saúde Animal:

\begin{abstract}
Além da distribuição, em caráter excepcional, de 2500 dólares para os funcionários CLT, a companhia concluiu, em março, o processo de cisão da Eli lilly e premia com ações os empregados que apresentem alta performance. O percentual varia de acordo com o cargo. Quem implementar ideias e obtiver sucesso com elas é premiado e amplamente reconhecido pela empresa. (VOCÊ S.A, 2019, p.163).
\end{abstract}

Os funcionários não comentaram sobre essa subcategoria. São poucas citações sobre prêmios, mas essa é uma prática que estimula os funcionários e, segundo a Lei 13.467 (BRASIL, 2017), o prêmio pode ser pago até duas vezes ao ano, como liberalidade do empregador em razão do desempenho superior ao esperado, em relação às rotinas, e não é considerado salário nem base de cálculo para o INSS. Pode ser usado para premiar e reconhecer os funcionários pelo esforço e pela entrega de atividades, projetos.

Na subcategoria PLR, empresas falaram sobre suas práticas. A participação nos lucros e resultados recebia elogios da empresa e dos funcionários. Já os funcionários comentaram sobre as práticas de PLR, podendo avaliar a contribuição individual ou grupal. Segundo Hoole e Hortz (2016), certas recompensas são melhores preditoras de envolvimento no trabalho do que outras, sendo que as empresas podem ter vários modelos de recompensa. Foram poucas citações sobre as práticas de PLR. Apesar da obrigatoriedade do seu pagamento, sabemos que nem todas as empresas pagam e que seria muito importante seu pagamento e reconhecimento da entrega e meritocracia dos seus funcionários. Na empresa Grupo KYLY:

Um dos programas de destaque é o de política de remuneração variável, que se desdobra em quatro prêmios. Há os mais tradicionais, com a participação nos lucros, que chega a dois salários por ano, com a possibilidade de um acréscimo de $10 \%$ para aqueles sem faltas ou advertência; e a comissão para os gerentes de loja. (VOCÊ S.A, 2019, p.163)

Ao se fazer o estudo das 50 empresas melhor avaliadas em gestão da remuneração e por se tratar de empresas de grande porte, estranha-se a pouca referência às práticas sobre PLR, por parte da empresa e dos funcionários, e as práticas citadas não são bem explicadas. A pesquisa realizada pela revista é extensa, mas não traz muitas informações sobre a existência das práticas de PLR, apesar de termos avaliado as 50 melhores 
empresas em remuneração e da obrigação do pagamento da PLR pelas empresas, conforme o Art. $7^{\circ}$ da Constituição Federal.

$\mathrm{Na}$ subcategoria Vantagens, as empresas comentaram sobre suas vantagens oferecidas aos funcionários e que, uma vez por mês, eles podiam levar os familiares para se divertirem nos resorts da empresa. Na empresa Alelo, quem recebia prêmios dos programas "Mandou bem" e "Atitude na empresa" ganhava destaque na TV corporativa. Nessas empresas, para os funcionários que estavam perto de se aposentarem, a empresa preparava work shops sobre finanças, empreendedorismo, para que esses profissionais saíssem preparados para um novo ciclo de vida. Essas foram algumas vantagens citadas pelas empresas. Já os funcionários não comentaram sobre as vantagens oferecidas pelas empresas. Isso nos faz entender que eles não reconheciam essas vantagens como significativas. Uma das empresas apresentou suas práticas, que é a possibilidade da obtenção de compra das ações da Vivo na Bolsa de Madri.

A subcategoria Benefícios foi muito comentada, tanto pelas empresas como pelos funcionários, apresentando benefícios variados, que foram muito elogiados. As empresas apresentaram suas práticas e os funcionários comentaram.

No Quadro 6, são apresentados os benefícios apresentados pelas empresas e os que foram comentados pelos funcionários.

Quadro 6 - Subcategoria: Benefícios

\begin{tabular}{|l|l|}
\hline \multicolumn{2}{|c|}{ BENEFÍCIOS } \\
\hline Citações das empresas & Citações dos funcionários \\
\hline Assistência odontológica & Assistência médica \\
\hline Auxílio construção e aquisição de móveis & Atendimento ambulatorial \\
\hline
\end{tabular}




\begin{tabular}{|l|l|}
\hline Assistência médica & Auxílio para graduação e pós-graduação \\
\hline Assistência psicológica & Creche na empresa \\
\hline Academia / Gympas & Refeitório \\
\hline Auxílio creche / Auxílio educação & \\
\hline $\begin{array}{l}\text { Auxílio jurídico / Bolsas de estudo de } \\
\text { graduação e pós-graduação }\end{array}$ & \\
\hline Complemento salarial para afastamentos & \\
\hline $\begin{array}{l}\text { Compra de ações da empresa / Curso de } \\
\text { inglês }\end{array}$ & \\
\hline $\begin{array}{l}\text { Desconto em aluguel de carro / Desconto } \\
\text { seguro automóvel / Desconto combustível } \\
\text { / Doação de fraudas para novos pais / } \\
\text { Empréstimo de bicicletas }\end{array}$ & \\
\hline Hospedagem em casa de praia & \\
\hline Inclusão da família no plano de saúde & \\
\hline $\begin{array}{l}\text { Previdência privada / Restaurante com } \\
\text { nutricionista }\end{array}$ & \\
\hline Vale Alimentação / Vale Refeição & \\
\hline $\begin{array}{l}\text { Total: 24 citações de benefícios pelas } \\
\text { empresas }\end{array}$ & $\begin{array}{l}\text { citações de benefícios pelos } \\
\text { funcionários }\end{array}$ \\
\hline
\end{tabular}

Fonte: Elaborado pela autora.

Os benefícios comentados pelas empresas não são os mesmos citados pelos funcionários, o que pode ser melhor alinhado entre a disponibilidade das empresas e as necessidades dos funcionários.

Pelo contexto avaliado, na unidade de registro de remuneração, quando colocadas perante os contextos, ou seja, as práticas comentadas pelas empresas e pelos funcionários, a subcategoria mais encontrada foi benefícios.

\section{CONSIDERAÇÕES FINAIS}

Entre as 12 categorias avaliadas e disponibilizadas pela revista, foi escolhida e estudada a categoria Gestão da Remuneração, analisando as políticas e práticas citadas e comentadas nas 50 empresas com as melhores avaliações nessa categoria.

Assim, voltamos ao objetivo principal deste trabalho, qual seja: analisar as políticas e práticas de gestão de remuneração nas melhores empresas para se trabalhar, eleitas pela Revista Você S.A., em 2019.

Analisando as citações das práticas encontradas nas 50 empresas melhor avaliadas em gestão de remuneração, a subcategoria que apresenta mais práticas adotadas pelas empresas foi Benefícios, levando ao entendimento de que essa subcategoria de remuneração faz parte da estratégia organizacional, o que reforça a posição de Pontes (2019), segundo a qual o sistema de remuneração estratégica consiste em empregar 
diferentes maneiras de remunerar as pessoas, dividindo a remuneração em parte fixa e parte variável e complementando com benefícios que irão se constituir em salário indireto. No entanto, o emprego de qualquer tipo de remuneração deve estar vinculado às estratégias organizacionais.

Não foi possível verificar o tipo de remuneração utilizada pelas organizações, se tradicional, baseada nos cargos, ou estratégica, baseada nos resultados, mas conclui-se que a remuneração estratégica desempenha um papel importante para melhorar a produtividade, visto que reduz o atrito dos funcionários, elevando os níveis de engajamento deles na organização e também os motiva a desenvolverem outras habilidades. É importante encontrar um senso de equilíbrio entre quais funcionários contribuem para uma organização e o que eles recebem de volta, em forma de recompensas e reconhecimento. Isso é crucialmente fundamental para sustentar os esforços extras que acompanham os trabalhadores. (D' SOUZA, 2018).

Logo, se entende que há espaço para a criação e divulgação de novas práticas voltadas para a remuneração: salário, bônus, prêmios, PLR, vantagens e benefícios, pois esses foram comentados pelas empresas e empregados, sendo que a subcategoria benefícios foi a mais comentada e reconhecida como parte estratégica das organizações.

Como contribuições deste estudo destacam-se as categorias de remuneração mais conhecidas pelos funcionários e divulgadas pelas empresas: salário, bônus, prêmios, PLR, vantagens e benefícios e a diferenciação entre a remuneração fixa e a remuneração estratégica, o que traz a teoria versus as práticas organizacionais. Conclui-se que é preciso conhecer a empresa, sua cultura, seu negócio e avançar em novos modelos de remuneração de funcionários, alinhados às estratégias organizacionais, pois muito se comenta sobre os modelos estratégicos como complemento salarial, mas a maioria das empresas ainda trabalha apenas com o modelo tradicional, com salário fixo, baseado em cargos. Esse cenário é reforçado pela conclusão da presente pesquisa, visto que a categoria mais comentada pelas empresas e pelos empregados é benefícios, que é uma remuneração indireta e fixa, e não uma remuneração estratégica, ligada aos resultados. Apesar de ser usada como estratégia de pagamento, por reduzir os custos.

Ainda como contribuição, permite uma reflexão sobre os modelos de remuneração existentes, a importância da divulgação do modelo adotado pela organização e os fatores tangíveis ou intangíveis utilizados e a possibilidade de escolha dos benefícios.

Este estudo não é uma exceção e, por isso, apresenta algumas limitações, que poderão orientar a realização de outros trabalhos que possam explorar os temas tratados 
aqui sob outras perspectivas, ou utilizando diferentes metodologias. O fato de este estudo analisar apenas os dados da publicação da Revista Você S.A. "As Melhores Empresas Para se Trabalhar de 2019" não permite uma comparação com resultados de publicações de anos anteriores. Apesar de haver anualmente mudanças nos critérios de avaliação adotados pela revista, algumas análises transversais poderiam ser realizadas. Outra limitação diz respeito ao fato de a escolha de comparação entre as empresas ter sido realizada analisando-se apenas as práticas adotadas pelas empresas, na gestão de remuneração. Essa perspectiva gera oportunidade para a realização de novos trabalhos que avaliem outras ou mais práticas das organizações listadas pela revista.

\section{REFERÊNCIAS}

ARAUJO, L. C.; GARCIA, A. A. Gestão de pessoas. São Paulo: Atlas. 2010.

ARELLANO, E. B.; CESAR, A. M. Gestão de pessoas: nas empresas contemporâneas brasileiras. Rio de Janeiro: Elsevier. 2017.

BARDIN, L. Análise de conteúdo. Trad. L. A. Reto e A. Pinheiro. São Paulo: Edição 70. 2016.

BASILE, C. R. Direito do trabalho: remuneração, duração do trabalho e direito coletivo. Coleção sinopses jurídicas. 8. ed. São Paulo: Saraiva Educação. 2018. v. 28.

BRASIL. Lei 13.467, de 13 de julho de 2017. Altera a Consolidação das Leis do Trabalho (CLT), aprovada pelo Decreto-Lei ${ }^{\circ} 5.452$, de $1^{\circ}$ de maio de 1943 , e as Leis $n$ ${ }^{\circ} 6.019$, de 3 de janeiro de 1974, 8.036, de 11 de maio de 1990, e 8.212, de 24 de julho de 1991, a fim de adequar a legislação às novas relações de trabalho. Diário Oficial da União. Brasília. 2017.

BRASIL. Lei $\mathrm{n}^{\circ} 10101$, de 19 de dezembro de 2000. Dispõe sobre a participação dos trabalhadores nos lucros ou resultados da empresa e dá outras providências. Diário Oficial da União. Brasília. 2000.

D'SOUZA, S. Employee Rewards in HRM and its impact on Employee Engagement in an Organization. International Journal of Trend in Scientific Research and Development (IJTSRD), v. 2, n. 4, p. 1425-1432, 2018.

DUTRA, Joel Souza. Gestão e carreiras: a pessoa, a organização e as oportunidades. 2. ed. 2. Reimpr. São Paulo: Atlas, 2019.

VOCÊ S/A. Edição Especial VOCÊ S/A. Guia Você S/A: As Melhores Empresas para Você Trabalhar. São Paulo: Editora Abril. 2019.

GIL, A. C. Métodos e técnicas de pesquisa social. 5. ed. São Paulo:Atlas. 2007.

GRUBB, V. M. Conflito de gerações: desafios e estratégias para gerenciar quatro gerações no ambiente de trabalho. São Paulo: Autêntica Business. 2018. 
HIPÓLITO, J. A. M. Sistema de recompensas: uma abordagem atual. In: FLEURY, M.T. (coord). As pessoas na organização. 4. ed. São Paulo: Gente. 2002.

HOOLE, C.; HOTZ, G. The impact of a total reward system of work engagement. SA Journal of Industrial Psychology/SA Tydskrif virBedryfsielkunde, v. 42, n. 1, a1317, 2016.

HUCZOK, R.; LEME, R. Remuneração: cargos e salários ou competências? $2^{\circ}$ reimpressão. Rio de Janeiro: Qualitymark Editora, 128p. 2014.

KANAPATHIPPILLAI, S.; MIHRET, D.; JOHL, S. Remuneration Committees and Attribution Disclosures on Remuneration Decisions: Australian Evidence. Journal of Business Ethics, v. 158, n. 4, p. 1036-1082, 2019.

MARRAS, J. P. Administração de recursos humanos: do operacional ao estratégico. 15. ed. São Paulo: Saraiva. 2016. 352 p.

MERCER. Relatório de pesquisa People Risks in M\&A Transactions. Melhor gestão de pessoas-edição especial do CONARH, p. 92-93. 2017.

MORIATY, J. Against pay secrecy. Journal of Applied Philosophy, v. 35, n. 4, p. 689-704, may. 2018.

NAWAZ, M. S.; PANGIL, F. The relationship between human resource development factors, career growth and turnover intention: the mediating role of organizational commitment. Managemet Science Letters, v. 6, p. 157-176, 2016.

ORSI, A. Gestão da remuneração. In: ARELLANO, E.; ORSI, A.; CESAR, A. M.; RODRIGUES, M.; BAYMA, L.; CAMARGO, Y. et al. Gestão de pessoas: nas empresas contemporâneas brasileiras Rio de Janeiro: Elsevier. 2017. p

PEREIRA, M. C. RH essencial: gestão estratégica de pessoas e competências. São Paulo: Saraiva. 2014.

PONTES, B. R. Administração de cargos e salários: carreiras e remuneração. 19. ed. São Paulo: LTr. 2019.

RIBEIRO, A. D. Gestão de pessoas. São Paulo: Saraiva Educação. 2019.

SAN, O. T.; THEEN, Y. M.; HENG., T. B. The Reward Strategy and Performance Measurement (Evidence from Malaysian Insurance Companies). International Journal of Business- Humanities and Technology, v. 2, n. 1, p. $211-223.2012$

THEOTÔNIO, K. S.; REIS NETO, M. T.; LOPES, S. A. A remuneração no Brasil: uma análise segundo os aspectos legais. XXXVII Encontro da Anpad, p. 16. 2013.

ULRICH, D. Os campeões de recursos humanos: inovando para obter os melhores resultados. 3. Reimpr. São Paulo: Futura. 2000.

VERGARA, S. C. Projetos e relatórios de pesquisa em administração. 5.ed. São Paulo: Atlas, 2004. 
Análise da gestão de remuneração nas melhores empresas para trabalhar em 2019, no Brasil

WOOD JUNIOR, T.; PICARELLI, F. V. Remuneração estratégica: a nova vantagem competitiva. 3. ed. São Paulo: Editora Atlas. 2004.

WOOD JUNIOR, T. Remuneração estratégica: a nova vantagem competitiva. 3. ed. São Paulo: Atlas. 2009. 